\title{
Primary and secondary dissociation pathways in the ultraviolet photolysis of $\mathrm{Cl}_{2} \mathrm{O}$
}

\author{
Christine M. Nelson, Teresa A. Moore, and Mitchio Okumura ${ }^{a)}$ \\ Arthur Amos Noyes Laboratory of Chemical Physics, ${ }^{\text {b) }}$ California Institute of Technology, Pasadena, \\ California 91125
}

Timothy K. Minton ${ }^{\text {a) }}$

Jet Propulsion Laboratory, California Institute of Technology, Pasadena, California 91109

(Received 9 December 1993; accepted 24 February 1994)

\begin{abstract}
The photodissociation of dichlorine monoxide $\left(\mathrm{Cl}_{2} \mathrm{O}\right)$ at 308,248 , and $193 \mathrm{~nm}$ was studied by photofragment translational energy spectroscopy. The primary channel upon excitation at 308 and $248 \mathrm{~nm}$ was $\mathrm{Cl}-\mathrm{O}$ bond fission with production of $\mathrm{ClO}+\mathrm{Cl}$. A fraction of the $\mathrm{ClO}$ photoproducts also underwent spontaneous secondary dissociation at $248 \mathrm{~nm}$. The center-of-mass translational energy distribution for the $\mathrm{ClO}+\mathrm{Cl}$ channel at $248 \mathrm{~nm}$ appeared to be bimodal with a high energy component that was similar in shape to the $308 \mathrm{~nm}$ distribution and a second, low energy component with a maximum close to the threshold for the $2 \mathrm{Cl}+\mathrm{O}\left({ }^{3} \mathrm{P}\right)$ channel. Observation of a bimodal distribution suggests that two pathways with different dissociation dynamics lead to $\mathrm{ClO}+\mathrm{Cl}$ products. The high product internal energy of the second component raises the possibility that $\mathrm{ClO}$ is formed in a previously unobserved spin-excited state $a^{4} \Sigma^{-}$. Following excitation at $193 \mathrm{~nm}$, a concerted dissociation pathway leading to $\mathrm{Cl}_{2}+\mathrm{O}$ was observed in addition to primary $\mathrm{Cl}-\mathrm{O}$ bond breakage. In both processes, most of the diatomic photofragments were formed with sufficient internal energy that they spontaneously dissociated. The time-of-flight distributions of the $\mathrm{Cl}_{2}+\mathrm{O}$ products suggest that these fragments are formed in two different channels $\mathrm{Cl}_{2}\left({ }^{3} \Pi\right)+\mathrm{O}\left({ }^{3} P\right)$ and $\mathrm{Cl}_{2}\left(X^{1} \Sigma\right)+\mathrm{O}\left({ }^{1} D\right)$.
\end{abstract}

\section{INTRODUCTION}

The importance of chlorine-catalyzed ozone loss cycles in the stratosphere has motivated studies of the photochemistry of chlorine-containing compounds. Among the chlorine oxides, dichlorine monoxide $\left(\mathrm{Cl}_{2} \mathrm{O}\right.$, also referred to as chlorine monoxide) is currently thought to play a minor role in stratospheric chemistry. However, a study of its photochemistry can deepen our understanding of the photochemistry of related molecules; furthermore, $\mathrm{Cl}_{2} \mathrm{O}$ is frequently used in laboratory studies of chlorine/oxygen chemistry, in flow tube studies as a photolytic precursor for $\mathrm{ClO}$, and in molecular beam studies to calibrate the relative detector sensitivity for $\mathrm{Cl}$ and $\mathrm{ClO}$ fragments. Correct interpretation of such experiments requires characterization of $\mathrm{Cl}_{2} \mathrm{O}$ photochemistry, but the photodecomposition pathways are still uncertain, especially at shorter wavelengths $(\lambda<300 \mathrm{~nm})$.

$\mathrm{Cl}_{2} \mathrm{O}$ possesses a complex manifold of electronically excited states. The four highest filled molecular orbitals of $\mathrm{Cl}_{2} \mathrm{O}$ are nearly degenerate nonbonding and weakly antibonding orbitals, and excitation of electrons from these orbitals gives rise to several transitions in the visible and ultraviolet. The absorption spectrum contains overlapping continuous bands between 660 and $220 \mathrm{~nm}$. The most prominent of those features are a maximum at $255 \mathrm{~nm}$ and a shoulder at $280 \mathrm{~nm}$ (see Fig. 1). ${ }^{1}$ Two additional strong features appear in the vacuum ultraviolet, a strong continuous band with a peak at $171.3 \mathrm{~nm}$ (whose onset at $220 \mathrm{~nm}$ can be seen

\footnotetext{
2) Authors to whom correspondence should be addressed.

b) Contribution number 8901 .
}

in Fig. 1) and a structured Rydberg transition with an origin at $162.9 \mathrm{~nm}^{2}$

Earlier experiments on the UV photochemistry of $\mathrm{Cl}_{2} \mathrm{O}$ involved the measurement of the final product quantum yields at high reactant pressures and the determination of the chain propagation mechanisms. Finkelnburg et al. ${ }^{3}$ investigated both the direct and chlorine-sensitized photochemical decompositions of $\mathrm{Cl}_{2} \mathrm{O}$ at 313,365 , and $436 \mathrm{~nm}$. From an observed final $\mathrm{Cl}_{2}$ product quantum yield of 3.5 , they deduced that ${ }^{4}$

$$
\mathrm{Cl}_{2} \mathrm{O}+h \nu \rightarrow \mathrm{ClO}+\mathrm{Cl}, \quad \Delta H_{0}^{\circ}=32.9 \mathrm{kcal} / \mathrm{mol}
$$

was the initial $\mathrm{Cl}_{2} \mathrm{O}$ decomposition step. Several studies later suggested that atomic oxygen is produced directly from $\mathrm{Cl}_{2} \mathrm{O}$ by photolysis at shorter wavelengths

$$
\begin{array}{ll}
\mathrm{Cl}_{2} \mathrm{O}+h \nu \rightarrow 2 \mathrm{Cl}+\mathrm{O}\left({ }^{3} P\right), & \Delta H_{0}^{\circ}=96.4 \mathrm{kcal} / \mathrm{mol}, \\
\mathrm{Cl}_{2} \mathrm{O}+h \nu \rightarrow \mathrm{Cl}_{2}+\mathrm{O}\left({ }^{3} P\right), & \Delta H_{0}^{\circ}=39.2 \mathrm{kcal} / \mathrm{mol} .
\end{array}
$$

Schumacher and Townend $d^{5}$ observed an increased quantum yield of 4.5 upon irradiation in the wavelength range 235$275 \mathrm{~nm}$. They proposed that channel (2) was the only $\mathrm{Cl}_{2} \mathrm{O}$ dissociation pathway occurring below $275 \mathrm{~nm}$. To explain the unit increase in quantum yield at shorter wavelengths, they had to assume that oxygen atoms do not react with $\mathrm{ClO}$; however, subsequent experiments have shown that the $\mathrm{O}+\mathrm{Cl}_{2} \mathrm{O}$ reaction is fast. ${ }^{6}$ Edgecomb et al. reexamined $\mathrm{Cl}_{2} \mathrm{O}$ photochemistry by flash photolysis at $\lambda>281 \mathrm{~nm}$ and direct detection of $\mathrm{ClO}$ intermediates. ${ }^{7}$ They suggested that the increased quantum yield observed by Schumacher and Townend was due to limited initial formation of $\mathrm{O}$ atoms by reaction (2), followed by rapid reaction of these atoms with 


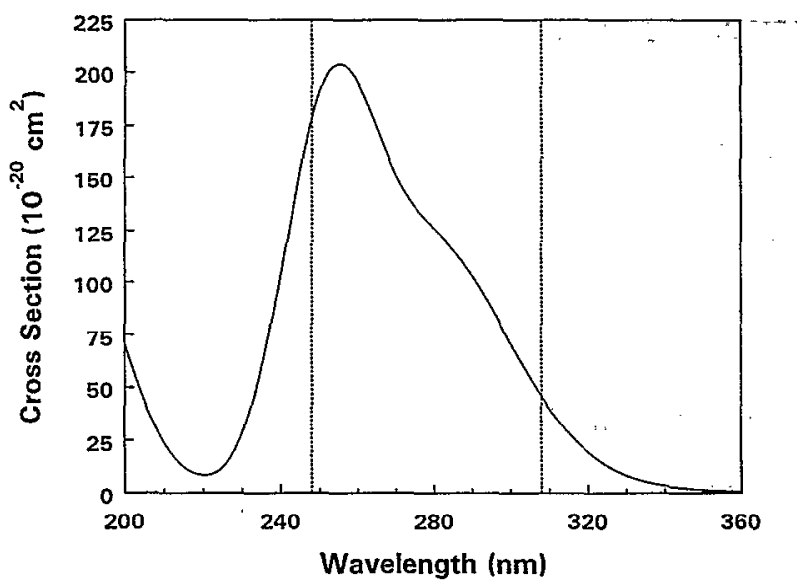

FIG. 1. The absorption spectrum of $\mathrm{Cl}_{2} \mathrm{O}$. Points are taken from Ref. 17 based on an evaluation of published spectra in Ref. 1.

$\mathrm{Cl}_{2} \mathrm{O}$. In a more recent flash-photolysis study, Basco and Dogra found an average final product quantum yield of $\mathrm{Cl}_{2}$ of $4.9 \pm 1.0$ at all wavelengths, regardless of the presence of $\mathrm{Cl}_{2}{ }^{8}$. When they photolyzed $\mathrm{Cl}_{2} \mathrm{O}$ at $\lambda<310 \mathrm{~nm}$, they also observed vibrationally excited oxygen $\mathrm{O}_{2}^{*}$, which they conjectured could only be formed by reactions of atomic oxygen

$$
\begin{aligned}
& \mathrm{O}+\mathrm{Cl}_{2} \mathrm{O} \rightarrow 2 \mathrm{Cl}+\mathrm{O}_{2}^{*}, \\
& \mathrm{O}+\mathrm{ClO} \rightarrow \mathrm{Cl}+\mathrm{O}_{2}^{*} .
\end{aligned}
$$

They inferred that there were two possible sources of oxygen atoms-photolysis of $\mathrm{Cl}_{2} \mathrm{O}$ and photolysis of $\mathrm{ClO}$. Their data was most consistent with $\mathrm{O}$ atoms formed entirely by secondary photodissociation of the primary $\mathrm{ClO}$ products

$$
\mathrm{ClO}+h \nu \rightarrow \mathrm{Cl}+\mathrm{O} \text {. }
$$

They concluded that no compelling case could be made for atomic oxygen produced directly from photolysis of $\mathrm{Cl}_{2} \mathrm{O}$. Prior to 1989 , there was thus conflicting evidence for reaction (2) or reaction (3). All of these earlier studies relied on indirect detection of $\mathrm{O}$ atoms and an incomplete understanding of the reaction kinetics, especially of the $\mathrm{ClO}$ selfreaction.

Sander and Friedl used $\mathrm{Cl}_{2} \mathrm{O}$ photolysis to form $\mathrm{ClO}$ in a recent flow tube study of the $\mathrm{BrO}+\mathrm{ClO}$ reaction. ${ }^{9}$ When they photolyzed $\mathrm{Cl}_{2} \mathrm{O}$ with broadband radiation from a xenon flashlamp $(\lambda>180 \mathrm{~nm}$ through quartz $)$ in the presence of $\mathrm{Br}_{2}$, they detected $\mathrm{BrO}$ products as well. $\mathrm{BrO}$ could only be produced by the reaction

$$
\mathrm{O}+\mathrm{Br}_{2} \rightarrow \mathrm{BrO}+\mathrm{Br} \text {. }
$$

They concluded that atomic oxygen was formed directly from $\mathrm{Cl}_{2} \mathrm{O}$ photolysis by either reaction (2) or reaction (3). From the $\mathrm{BrO}$ yield, they obtained an $\mathrm{O}$ atom quantum yield of $0.25 \pm 0.05$ integrated over the intensity distribution of the flashlamp. They could not measure the wavelength dependence of the quantum yield, nor could they identify the specific $\mathrm{Cl}_{2} \mathrm{O}$ dissociation channels leading to $\mathrm{O}$ atom production.
.. The primary and secondary channels in the photodissociation of $\mathrm{Cl}_{2} \mathrm{O}$ can be probed and differentiated by the technique of photofragment translational energy spectroscopy, which allows the direct detection of photoproducts and the determination of their translational energy and angular distributions. We have employed this method to study the UV photodissociation of dichlorine monoxide. In an earlier communication, ${ }^{10}$ we used the photolysis of $\mathrm{Cl}_{2} \mathrm{O}$ at $308 \mathrm{~nm}$ to calibrate the relative detection efficiencies of our mass spectrometer for $\mathrm{Cl}$ and $\mathrm{ClO}$ photofragments. In this paper, we present full results of the study of dichlorine monoxide photolysis at 308 and $248 \mathrm{~nm}$, as well as preliminary data at $=193 \mathrm{~nm}$. The $\mathrm{ClO}+\mathrm{Cl}$ and $\mathrm{Cl}_{2}+\mathrm{O}\left({ }^{3} P\right)$ channels are energetically accessible at all three wavelengths, but the $\mathrm{Cl}+\mathrm{Cl}+\mathrm{O}\left({ }^{3} P\right)$ channel can only be reached at 193 and 248 $\mathrm{nm}$. By photolyzing $\mathrm{Cl}_{2} \mathrm{O}$ at these wavelengths, we can compare the dissociation dynamics upon excitation to different regions of the $\mathrm{Cl}_{2} \mathrm{O}$ absorption spectrum.

\section{EXPERIMENT}

The experimental apparatus and methods are described in detail elsewhere, ${ }^{11}$ and only a brief outline is presented here. A continuous molecular beam of $\mathrm{Cl}_{2} \mathrm{O}$ was formed by passing helium over the surface of liquid $\mathrm{Cl}_{2} \mathrm{O}$ (vapor pressure of 6.9 Torr at $-74^{\circ} \mathrm{C}$ ) and expanding the mixture through a $0.1 \mathrm{~mm}$ diameter water-cooled glass nozzle $\left(4.9^{\circ} \mathrm{C}\right)$ at a total stagnation pressure of 200 Torr. A skimmer confined the beam to an angular divergence of $3.4^{\circ}$. A rectangular slit aperture further collimated the beam to a 2.3 $\mathrm{mm} \times 3.0 \mathrm{~mm}$ spot in the interaction region. The nozzle was $4.8 \mathrm{~cm}$ from the interaction volume, where the molecular beam intersected the focused, unpolarized beam of a pulsed excimer laser. The density of $\mathrm{Cl}_{2} \mathrm{O}$ in the interaction volume was approximately $10^{11} \mathrm{~cm}^{-3}$. After a laser pulse, the resulting photoproducts scattered out of the interaction region and were detected off the beam axis with a mass spectrometer rotatable in the plane of the molecular beam and laser. The distance from the photolysis volume to the Brinks ionizer of the mass spectrometer was $34.1 \mathrm{~cm}$. Time-of-flight (TOF) spectra of the fragments were recorded with a multichannel scaler in $2 \mu$ s steps. Electron energies in the ionizer were nominally $160 \mathrm{eV}$ (set by optimizing ion signal), but the actual energy was lower due to space-charge effects at the emission currents used in these experiments. The velocity distribution of the parent molecular beam was determined by chopping the beam with a slotted disk and measuring the TOF distribution with the detector positioned on the beam axis. The correction for the flight time of ions from the ionizer to the Daly detector was found to be $t=3.54(\mathrm{~m} / \mathrm{e})^{1 / 2}$ $\mu$ s.

$\mathrm{Cl}_{2} \mathrm{O}$ synthesis followed techniques presented in the literature. ${ }^{12}$ The main impurity, $\mathrm{Cl}_{2}$, was removed by pumping on the sample at $-118^{\circ} \mathrm{C}$ (ethanol slush bath). Running the molecular beam prior to performing the experiment served as a further purification step by preferentially removing the more volatile $\mathrm{Cl}_{2}$. After the molecular beam velocity had stabilized, data collection proceeded.

A Lambda Physik EMG 101 excimer laser was used to provide the excitation wavelengths of 193,248 , or $308 \mathrm{~nm}$. 
Pulse energies in the interaction region were $13-25,48-60$, or $9-22 \mathrm{~mJ}$ and spot sizes were (width by height) $2.3 \times 3.5$, $4.7 \times 2.4$, or $3.3 \times 1.4 \mathrm{~mm}$, respectively. We measured the fluence dependence of the $m / e=35$ TOF spectra at all wavelengths in order to identify and minimize contributions from stimulated secondary dissociation of primary $\mathrm{ClO}$ photofragments. The laser pulse energy was attenuated to the levels quoted above with quartz plates until the shape of the $\mathrm{m} / \mathrm{c}$ $=35$ TOF spectra no longer varied with intensity.

TOF spectra were recorded at $m / e=35\left(\mathrm{Cl}^{+}\right), 51$ $\left(\mathrm{ClO}^{+}\right), 70\left(\mathrm{Cl}_{2}^{+}\right)$, and $16\left(\mathrm{O}^{+}\right)$and at detector angles from $10^{\circ}$ to $60^{\circ}$. Each TOF spectrum was averaged for 100000 to 500000 laser pulses. Angular distributions at 248 and 308 $\mathrm{nm}$ were recorded at $m / e=51$ over the range $10^{\circ}-50^{\circ}$. The $248 \mathrm{~nm}$ distribution was made in $10^{\circ}$ increments with four scans of 10000 laser pulses each for a total of 40000 laser pulses at each angle. The $308 \mathrm{~nm}$ distribution was recorded in $5^{\circ}$ increments with six scans for a total of 60000 laser pulses at each angle. The angular distribution of the $m / e=16$ signal from $193 \mathrm{~nm}$ photolysis was measured from $10^{\circ}$ to $60^{\circ}$ in two scans for a total of 20000 shots at each angle.

\section{RESULTS AND ANALYSIS}

Fragments recoiling upon dissociation can be characterized by a center-of-mass (c.m.) translational energy distribution $P\left(E_{T}\right)$ and a c.m. angular distribution $w(\theta) \propto 1+\beta P_{2}(\cos \theta)$, where $E_{T}$ is the total c.m. translational energy of the products, $\theta$ is the angle between the electric field vector of the radiation and the relative product velocity (recoil) vector, and $P_{2}$ is the second Legendre polynomial. ${ }^{13}$ The available energy $E_{\text {avl }}=h \nu-\Delta H_{0}^{\circ}$, is partitioned between the c.m. translational energy $E_{T}$ and fragment internal energy $E_{\text {int }}$. The anisotropy parameter $\beta$, which is determined by the angle between the transition moment and recoil vector, varies from 2 (parallel) to -1 (perpendicular). If the dissociation is not instantaneous, the molecule will have time to rotate. Even partial averaging over molecular orientations by rotation reduces the observed anisotropy and diminishes the value of $\beta .{ }^{14}$ For linear molecules with lifetimes greater than a rotational period, $\beta$ is reduced by a factor of 4 ; for polyatomics, $\beta$ can approach zero. The TOF spectra are measured in the laboratory (LAB) frame at fixed detector angles. The $P\left(E_{T}\right)$ and $w(\theta)$ distributions are related to velocity and angular distributions in the $\mathrm{LAB}$ frame by a c.m.-to- $\mathrm{LAB}$ coordinate transformation, with intensities scaled by the appropriate Jacobian determinant. ${ }^{15}$ In analyzing the data for a given channel, we seek to find the c.m. distributions which best fit the observed TOF spectra at all laboratory angles.

We determine the anisotropy parameter $\beta$ for each primary channel by fitting the recorded angular distribution. Each TOF spectrum is then fit by a forward convolution method $^{15}$ in which a trial numerical c.m. translational energy distribution is convoluted with experimental parameters and the c.m. angular distribution, and then transformed into a TOF spectrum in the $\mathrm{LAB}$ frame. This procedure is repeated with the $P\left(E_{T}\right)$ function and $\beta$ parameter iteratively adjusted until the TOF spectra predicted by a single $P\left(E_{T}\right)$ distribu-

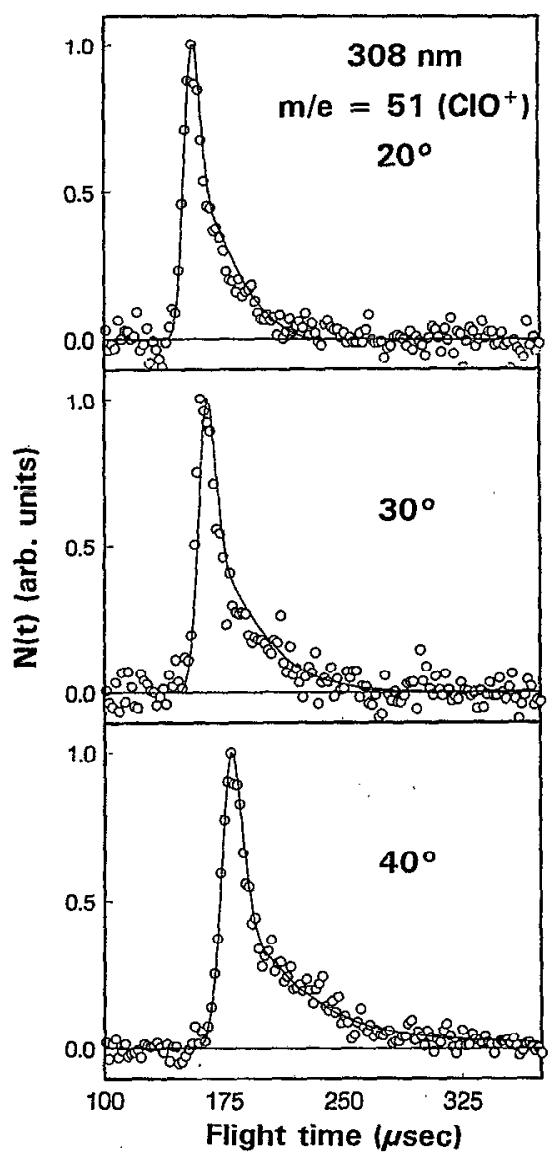

FIG. 2. Laboratory TOF distributions of $m / e=51$ at $308 \mathrm{~nm}$ for three detector angles. The solid lines are the best fits.

tion satisfactorily fit the data at all angles. We have not attempted to model the secondary dissociation of the primary photofragments in the current analysis.

In many cases, we recorded TOF spectra for both products from a primary two body dissociation channel and could therefore exploit the conservation of linear momentum to confirm our assignment. The two fragments recoil with equal and opposite momenta in the c.m. frame of reference, and the TOF spectra of both products are described by the same c.m. translational energy $P\left(E_{T}\right)$ and angular $w(\theta)$ distributions. We could thus use the c.m. distribution obtained by fitting the TOF spectra of one product to predict that of its counterfragment.

\section{A. $308 \mathrm{~nm}$}

We observed photoproduct signals at $m / e=16,35$, and 51 from the photolysis of $\mathrm{Cl}_{2} \mathrm{O}$ at $308 \mathrm{~nm}$. The $m / e=51$ $\left(\mathrm{ClO}^{+}\right)$TOF spectra, shown in Fig. 2 for various laboratory angles, consisted of a sharp peak with a slow tail. These products had an anisotropic angular distribution that was fit with $\beta=0.5$. With the exclusion of cluster dissociation, the only plausible assignment for the $m / e=51$ signal is $\mathrm{ClO}$ formed in channel (1). The $P\left(E_{T}\right)$ distribution that fit the $\mathrm{ClO}^{+}$spectra is displayed in the upper panel of Fig. 3 .

In the $m / e=35$ TOF spectra shown in Fig. 4 , two peaks 


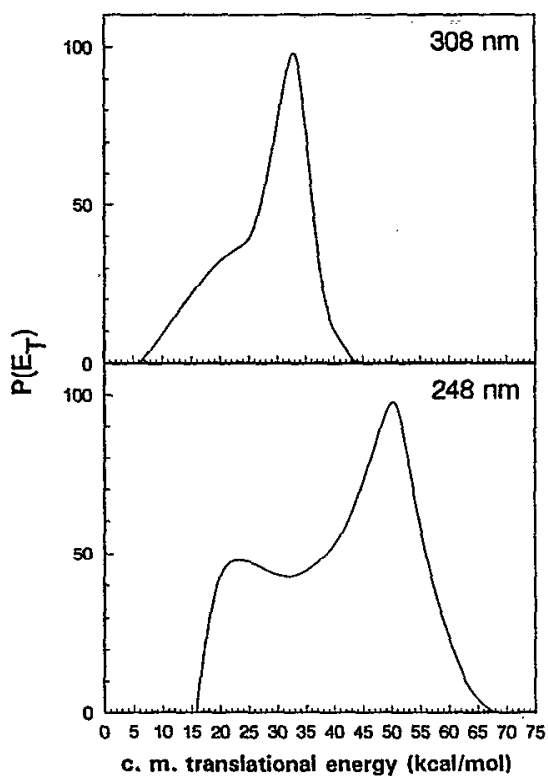

FIG. 3. The c.m. translational energy distributions $P\left(E_{T}\right)$ for the $\mathrm{ClO}+\mathrm{Cl}$ channel at 308 (upper) and $248 \mathrm{~nm}$ (lower) determined by fiting the m/e $=51$ TOF spectra at the respective wavelengths.

were apparent. The shape of the slower peak was identical to the $m / e=51$ peak after correcting for the difference between the $m / e=35$ and 51 ion flight times; therefore, we attributed this slower peak to cracking of $\mathrm{ClO}$ products in the ionizer to form $\mathrm{Cl}^{+}$. We assigned the fast, sharp peak to the $\mathrm{Cl}$ counterfragment. To confirm these assignments, we used the $P\left(E_{T}\right)$ distribution and $\beta$ parameter derived from the $\mathrm{ClO}$ analysis to fit the TOF spectra at $m / e=35$. $\mathrm{Cl}$ is formed in

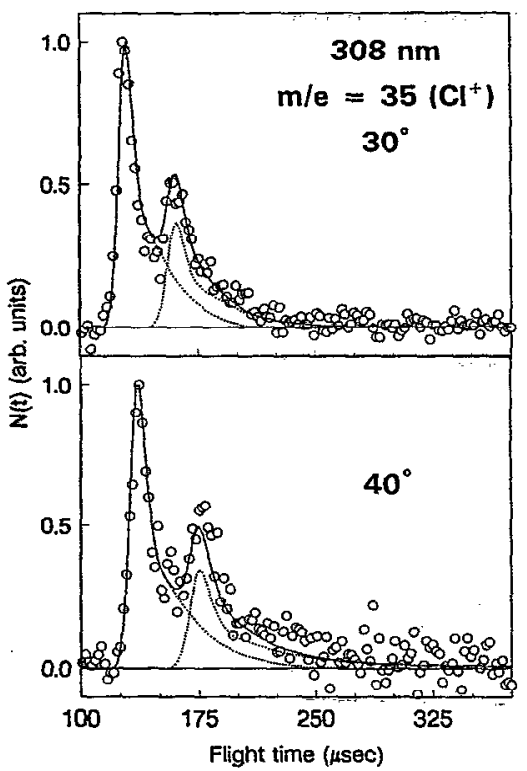

FIG. 4. Laboratory TOF distributions of $m / e=35$ at $308 \mathrm{~nm}$ for two detector angles. The solid lines are the calculated fits using the $P\left(E_{T}\right)$ distribution shown in the lower panel of Fig. 3. The dashed lines are the individual contributions from the $\mathrm{Cl}$ and $\mathrm{ClO}$ fragments.

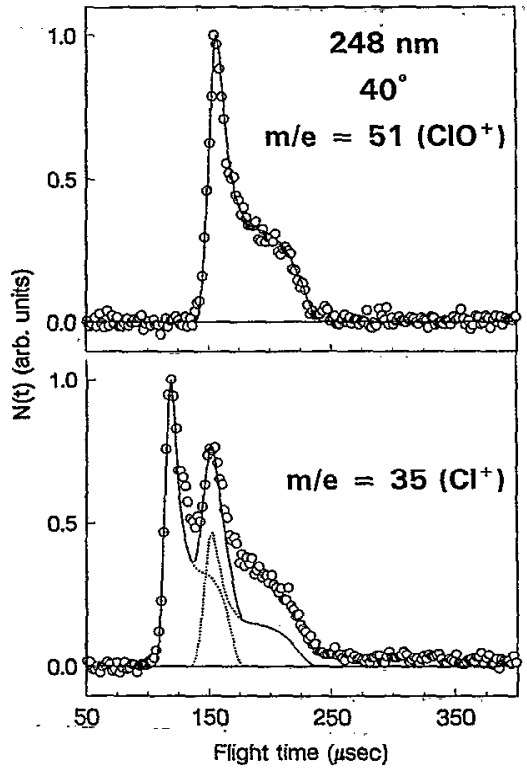

FIG. 5. Laboratory TOF distributions of $m / e=51$ and $m / e=35$ at $248 \mathrm{~nm}$ for a $40^{\circ}$ detector angle. The solid lines are the calculated fits using the $P\left(E_{T}\right)$ distribution shown in Fig. 3. The dashed lines in the $m / e=35$ TOF spectrum are the contributions from each product.

the same dissociation event as $\mathrm{ClO}$, so a fit to each component at $m / e=35$ can be calculated with the respective c.m.to-LAB transformation of the same $P\left(E_{T}\right)$ distribution. A complete fit of the TOF spectrum requires only one adjustable parameter, the relative scaling factor of the two components. The agreement between the predicted and observed TOF spectra shown in Fig. 4 verifies that the two components arise from the momentum-matched counterfragments formed in the $\mathrm{ClO}+\mathrm{Cl}$ channel and eliminates the possibility that the fragments were produced from the photodissociation of clusters. Given the success of the fit and the absence of signal at $m / e=70$, we conclude that only the $\mathrm{ClO}+\mathrm{Cl}$ channel is observed when photolyzing $\mathrm{Cl}_{2} \mathrm{O}$ at $308 \mathrm{~nm}$.

\section{B. $248 \mathrm{~nm}$}

The products detected at $248 \mathrm{~nm}$ exhibited TOF distributions (Fig. 5) similar to those obtained at $308 \mathrm{~nm}$. The $m / e=51$ spectra each had a single peak with a pronounced shoulder, while the $m / e=35$ spectra consisted of two peaks, the slower one identified as an ionizer crack of the product detected at $m / e=51$. We again fit the $m / e=51$ TOF spectra assuming that the signal came entirely from primary $\mathrm{ClO}$ products arising from the $\mathrm{ClO}+\mathrm{Cl}$ channel. A fit of the $m / e$ $=51$ angular distribution gave $\beta=0.5$. The $P\left(E_{T}\right)$ distribution (see the lower panel of Fig. 3) and $\beta$ parameter were then used to predict the $m / e=35$ TOF spectra (see Fig. 5). The predicted spectra malched the two main peaks observed in the $m / e=35$ spectra, although they do not account for all of the signal detected at $m / e=35$. The $\mathrm{ClO}+\mathrm{Cl}$ channel must be a major photodissociation channel at $248 \mathrm{~nm}$, but it is not the only dissociation pathway.

The discrepancy between the predicted and observed TOF spectra at $m / e=35$ appears as a broad background be- 
neath the $\mathrm{ClO}$ peak, suggesting that secondary $\mathrm{Cl}$ atom products are formed by spontaneous dissociation of primary $\mathrm{ClO}$ fragments. The available energy at $248 \mathrm{~nm}$ is $82 \mathrm{kcal} / \mathrm{mol}$, sufficient for secondary dissociation of ClO $\left(D_{0}=63.4 \mathrm{kcal} /\right.$ $\mathrm{mol})$. We observe a significant probability for $\mathrm{ClO}$ products formed near the dissociation limit, and formation of $\mathrm{ClO}$ with sufficient energy to dissociate is thus plausible.

Secondary photodissociation of the $\mathrm{ClO}$ photofragments ${ }^{16}$

$$
\mathrm{ClO}+h \nu \rightarrow \mathrm{Cl}+\mathrm{O}\left({ }^{\mathrm{l}} D\right)
$$

is also a possible source of atomic chlorine, because the absorption cross section of $\mathrm{ClO}$ at $248 \mathrm{~nm}$ is $\sigma_{\mathrm{ClO}}=3.2 \times 10^{-18}$ $\mathrm{cm}^{2}$, almost twice that of $\mathrm{Cl}_{2} \mathrm{O}\left(\sigma_{\mathrm{Cl}_{2} \mathrm{O}}=1.7 \times 10^{-18} \mathrm{~cm}^{2}\right) .{ }^{17}$ We were able to identify products from photolysis of $\mathrm{ClO}$ by examining the power dependence of the signal at $m / e=35$. At high laser fluences, new peaks appear that are forward and backward scattered from the primary $\mathrm{ClO}$ signal at $m / e$ $=35$, the result of photodissociation of the $\mathrm{ClO}$ fragments. These peaks are absent in the TOF spectra used in the data analysis, which were collected at reduced laser fluence. Stimulated secondary dissociation of $\mathrm{ClO}$ therefore does not contribute appreciably to the $\mathrm{Cl}$ atom signal seen in Fig. 5.

The $P\left(E_{T}\right)$ distribution derived from $m / e=51$ provides information only on the channel leading to $\mathrm{ClO}$ products stable enough to reach the detector. A complete $P\left(E_{T}\right)$ distribution could in principle be extracted from the TOF spectrum of the primary $\mathrm{Cl}$ atom fragment, but the slow tail of the primary distribution overlaps the secondary $\mathrm{Cl}$ atom signal, and these contributions could not be deconvoluted. The $P\left(E_{T}\right)$ distribution shown in Fig. 3 (lower panel) is therefore truncated at low energies and does not include the contribution from $\mathrm{ClO}$ that had undergone secondary dissociation.

The $P\left(E_{T}\right)$ distribution extends to a low energy threshold of $16 \mathrm{kcal} / \mathrm{mol}$. For products observed with total translational energy less than $19 \mathrm{kcal} / \mathrm{mol}$, the internal energy exceeds the $\mathrm{Cl}-\mathrm{O}$ bond dissociation energy. ${ }^{18}$ There are a number of ways to account for the observation of intact $\mathrm{ClO}$ products that appear to have internal energies above the dissociation limit. First, there are uncertainties of $2 \mathrm{kcal} / \mathrm{mol}$ in the fit and $0.5 \mathrm{kcal} / \mathrm{mol}$ in the $\mathrm{Cl}_{2} \mathrm{O}$ heat of formation. Second, energy could be partitioned into spin-orbit excitation of the $\mathrm{Cl}$ atom (the ${ }^{2} P_{1 / 2}$ state, $2 \mathrm{kcal} / \mathrm{mol}$ ), the $\mathrm{ClO}$ fragment (the ${ }^{2} \Pi_{1 / 2}$ state, $1 \mathrm{kcal} / \mathrm{mol}$ ), or both. Finally, $\mathrm{ClO}$ products could be metastable (bound by a centrifugal barrier) if formed in high rotational levels. The equilibrium bond angle is $110^{\circ}$, and in this geometry, a departing $\mathrm{Cl}$ atom would impart a large torque on the $\mathrm{ClO}$ fragment. With the use of either soft or rigid radical models, ${ }^{19}$ we estimate that as much as $40 \%-50 \%$ of the available energy could be initially partitioned into $\mathrm{ClO}$ rotation. $\mathrm{ClO}$ radicals in such high $J$ states would have centrifugal barriers supporting vibrational levels up to $6 \mathrm{kcal} / \mathrm{mol}$ above the $\mathrm{Cl}-\mathrm{O}$ dissociation limit. Although some $\mathrm{ClO}$ products thus appear to be metastable with internal energies above the dissociation limit, the inability to fit the $m / e=35$ TOF distribution in the same way that the $308 \mathrm{~nm}$ TOF was fit implies that a fraction of the $\mathrm{ClO}$ products are formed so internally hot that they dissociate.

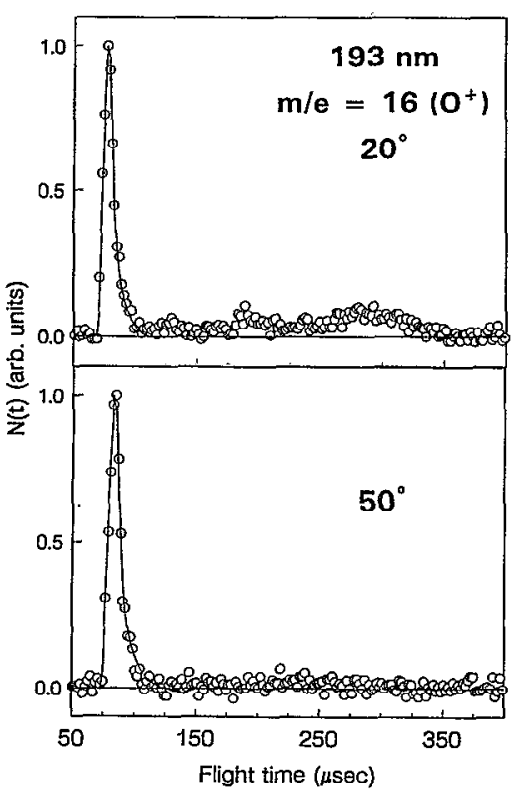

FIG. 6. Laboratory TOF distributions of $m / e=16$ at $193 \mathrm{~nm}$ for two detector angles. Circles are experimental points and the solid lines are the fits obtained using the $P\left(E_{T}\right)$ distribution for the $\mathrm{Cl}_{2}+\mathrm{O}$ channel shown in Fig. 7.

\section{C. $193 \mathrm{~nm}$}

The primary goal of our experiment was the study of $\mathrm{Cl}_{2} \mathrm{O}$ photolysis at 308 and $248 \mathrm{~nm}$. Our $193 \mathrm{~nm}$ study, while more exploratory, did reveal the main features of the dissociation dynamics at this wavelength.

The $m / e=16$ TOF spectra collected at $20^{\circ}$ and $50^{\circ}$ are shown in Fig. 6 . The angular distribution at this mass was fit with an anisotropy parameter of $\beta=0.4$. We observed a prominent peak arriving at short times that was not detected at other masses, indicating that the signal probably arises from $\mathrm{O}$ atom products from the concerted dissociation $\mathrm{Cl}_{2} \mathrm{O} \rightarrow \mathrm{Cl}_{2}+\mathrm{O}$. From fits of the TOF spectra (solid lines in Fig. 6), we obtained the $P\left(E_{T}\right)$ distribution shown in Fig. 7. This distribution had a peak at $E_{T}=42 \mathrm{kcal} / \mathrm{mol}$ and ended at $E_{T}=56 \mathrm{kcal} / \mathrm{mol}, 4 \mathrm{kcal} / \mathrm{mol}$ above the threshold for the $2 \mathrm{Cl}+\mathrm{O}\left({ }^{3} P\right)$ channel.

We tried to fit the TOF spectra of the counterfragment $\mathrm{Cl}_{2}$ at $m / e=70$ using the $P\left(E_{T}\right)$ distribution and anisotropy parameter $\beta$ obtained from fitting the $O$ atom data. The TOF distribution predicted by the full $P\left(E_{T}\right)$ distribution (the dashed line in Fig. 8) fit only the leading edge of the observed $m / e=70$ TOF spectrum. The discrepancy was removed (solid line of Fig. 8) if the $P\left(E_{T}\right)$ distribution was truncated (the shaded area in Fig. 7) by assuming that $\mathrm{Cl}_{2}$ fragments formed with internal energy greater than $D_{0}\left(\mathrm{Cl}_{2}\right)=57.2 \mathrm{kcal} / \mathrm{mol}$ dissociated before reaching the detector. From the difference between this truncated $P\left(E_{T}\right)$ distribution and the distribution obtained from the $\mathrm{O}$ atom data, we estimated that $87 \%$ of the $\mathrm{Cl}_{2}$ products undergo secondary dissociation. The $\mathrm{Cl}_{2}$ dissociation could only occur if the $\mathrm{O}$ atom counterfragments were in the ${ }^{3} P$ state.

A secondary peak at $m / e=70$ occurred at $t=225 \mu \mathrm{s}$ in the TOF spectrum at $20^{\circ}$ (see Fig. 8); products at these ve- 


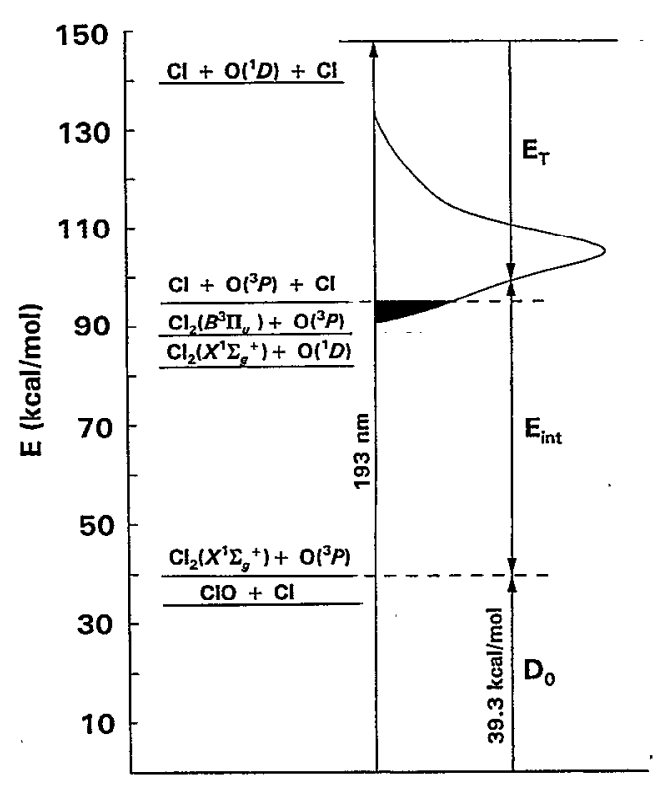

FIG. 7. The $P\left(E_{T}\right)$ distribution for the $\mathrm{Cl}_{2}+\mathrm{O}$ channel upon photolysis at $193 \mathrm{~nm}$ derived from TOF spectra at $m / e=16$, plotted against an energy level diagram. The shaded area shows the translational energies which correspond to internal energies less than the $\mathrm{Cl}-\mathrm{Cl}$ bond dissociation energy.

locities also contributed significantly to the slow peak observed at $30^{\circ}$. These $\mathrm{Cl}_{2}$ products were momentum matched with $\mathrm{O}$ atom counterfragments in the low energy tail of the $P\left(E_{T}\right)$ distribution in Fig. 7. Fragments at the peak had $E_{T}=19 \mathrm{kcal} / \mathrm{mol}$, while those at the leading edge had $E_{T}=30$ $\mathrm{kcal} / \mathrm{mol}$, corresponding to $E_{\text {int }}=79 \mathrm{kcal} / \mathrm{mol}$. We thus observed $\mathrm{Cl}_{2}$ signal well above the threshold for the

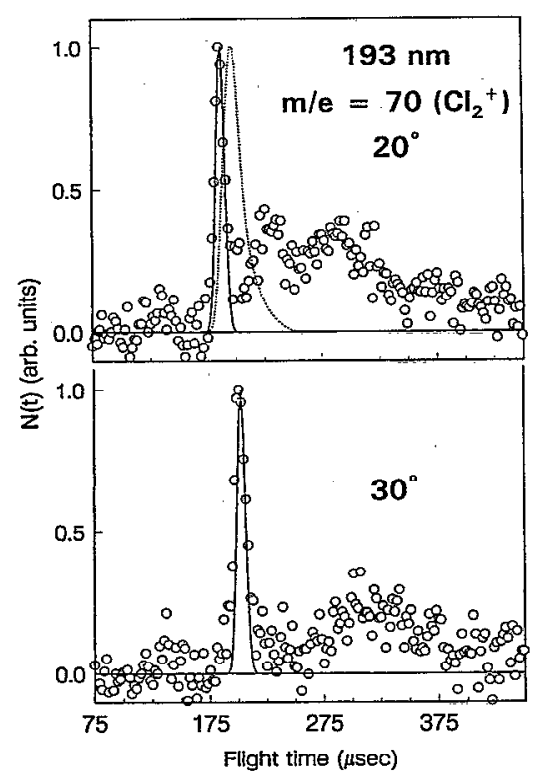

FIG. 8. Laboratory TOF distributions of $m / e=70$ at $193 \mathrm{~nm}$ for two detector angles. The dashed lines are the fits obtained using the full $P\left(E_{T}\right)$ distribution for the $\mathrm{Cl}_{2}+\mathrm{O}$ channel (shown in Fig. 7) determined from the $m / e=16$ signal. The solid lines are the fits calculated using the $P\left(E_{T}\right)$ distribution truncated at $E_{T} \geqslant D_{0}\left(\mathrm{Cl}_{2}\right)$.

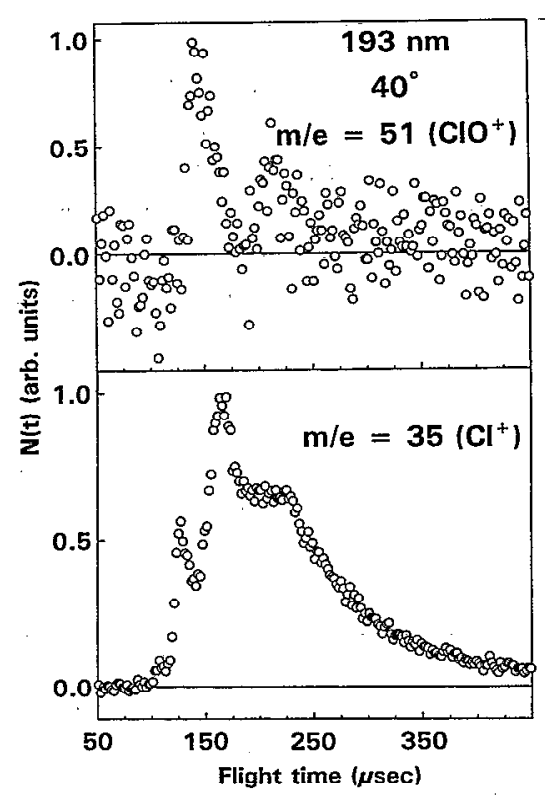

FIG. 9. Laboratory TOF distributions of $m / e=51$ and $m / e=35$ at $193 \mathrm{~nm}$ recorded at a $40^{\circ}$ detector angle.

$2 \mathrm{Cl}+\mathrm{O}\left({ }^{3} \mathrm{P}\right)$ channel. Bound $\mathrm{Cl}_{2}$ could only be observed if the $O$ atom was in an excited state. Therefore, we tentatively assign this signal to the pathway forming spin-excited oxygen atoms, the $\mathrm{Cl}_{2}\left(X^{1} \Sigma_{\mathrm{g}}^{+}\right)+\mathrm{O}\left({ }^{1} D\right)$ channel.

We observed signal at still longer arrival times in the $20^{\circ}$ TOF spectra at both $m / e=70$ and 16 (see Fig. 8). These peaks occurred at LAB velocities close to the parent beam velocity, indicating that the products were formed with little translational energy $\left(E_{T}=2\right.$ and $8 \mathrm{kcal} / \mathrm{mol}$ at $m / e=16$ and 70 , respectively, assuming the products are $\mathrm{Cl}_{2}+\mathrm{O}$ from the $\mathrm{Cl}_{2} \mathrm{O}$ monomer). The signal could arise from a number of channels, including cluster dissociation or, for the $m / e=16$ signal, secondary dissociation. The relatively low signal to noise ratio and lack of angular distribution information prevented further analysis.

The $m / e=35$ and 51 TOF spectra were recorded at $40^{\circ}$ (Fig. 9). Although we were unable to extract a $P\left(E_{T}\right)$ distribution, correlations between the two TOF spectra provide strong evidence for the $\mathrm{ClO}+\mathrm{Cl}$ channel. At $m / e=51$, a weak peak arriving at $152 \mu \mathrm{s}$ was apparent. If we were to assign this peak to $\mathrm{ClO}$ products from the $\mathrm{ClO}+\mathrm{Cl}$ channel, then $E_{T}$ would be $54 \mathrm{kcal} / \mathrm{mol}$, and the counterfragment $\mathrm{Cl}$ atoms would arrive at $110 \mu \mathrm{s}$, which corresponds to the fast signal in the $m / e=35 \mathrm{TOF}$ spectrum. In addition, the $\mathrm{Cl}$ atoms arriving at the leading edge $(t=100 \mu \mathrm{s})$ of the $\mathrm{m} / \mathrm{e}$ $=35 \mathrm{TOF}$ spectrum can be momentum matched with the fastest $\mathrm{ClO}$ at $130 \mu \mathrm{s}$ with $E_{T}=82 \mathrm{kcal} / \mathrm{mol}$. The $m / e=51$ TOF spectrum fell off rapidly at $t \approx 155 \mu \mathrm{s}$, coinciding with the onset for secondary dissociation of the $\mathrm{ClO}$ fragments, i.e., $E_{\text {int }}>D_{0}(\mathrm{ClO})$.

The TOF spectrum at $m / e=35$ consisted of a number of superimposed peaks (the lower panel of Fig. 9). Sources of $m / e=35$ signal include cracking of $\mathrm{Cl}_{2}$ and $\mathrm{ClO}$ in the ionizer to form $\mathrm{Cl}^{+}$, primary $\mathrm{Cl}$ photofragments formed via the $\mathrm{Cl}+\mathrm{ClO}$ channel, atomic chlorine from spontaneous second- 
ary dissociation of $\mathrm{ClO}$ and $\mathrm{Cl}_{2}$, and possibly concerted three body decomposition to $2 \mathrm{Cl}+\mathrm{O}$. Extensive secondary dissociation was evident. The peak at $127 \mu$ s appears to arise from $\mathrm{Cl}$ photofragments that are momentum matched to $\mathrm{ClO}$ products that undergo spontaneous secondary dissociation and give rise to the strong $m / e=35$ peak at $165 \mu \mathrm{s}$.

Fragmentation to $2 \mathrm{Cl}+\mathrm{O}$ appears to be a major channel in the photolysis of $\mathrm{Cl}_{2} \mathrm{O}$ at $193 \mathrm{~nm}$; however, we were unable to deconvolute the strongly overlapping velocity distributions from these secondary channels and thus could not measure the relative yields for the various channels. Atomic fragments could also arise from a concerted three body process, but we were unable to identify such a channel because of the complexity of the $m / e=35$ TOF spectrum and the difficulty in modeling three body dissociation dynamics.

\section{DISCUSSION}

\section{A. $\mathrm{ClO}+\mathrm{Cl}$ channel}

We have observed simple $\mathrm{Cl}-\mathrm{O}$ bond fission leading to $\mathrm{ClO}+\mathrm{Cl}$ products at all three wavelengths. The $\mathrm{ClO}+\mathrm{Cl}$ channel is the only dissociation channel following excitation at $308 \mathrm{~nm}$, a major channel at $248 \mathrm{~nm}$, and a minor channel at $193 \mathrm{~nm}$. These findings agree with Finkelnburg et al., ${ }^{3}$ who concluded that above $300 \mathrm{~nm}$, the only photodissociation pathway is $\mathrm{ClO}+\mathrm{Cl}$. Our results contradict the conclusion of Schumacher and Townend ${ }^{5}$ that photolysis of $\mathrm{Cl}_{2} \mathrm{O}$ from 235 to $275 \mathrm{~nm}$ produced only atomic fragments $2 \mathrm{Cl}+\mathrm{O}$.

The dissociation dynamics at 308 and $248 \mathrm{~nm}$ appear to be similar, having identical values for the $\beta$ parameter and sharing common features in their $P\left(E_{\tau}\right)$ distributions. $\beta=0.5$ implies that the angle between the transition moment and the recoil velocity vector is $\leqslant 45^{\circ}$. The transition dipole is thus approximately in plane and perpendicular to the $C_{2 v}$ symmetry $\left(A_{1}\right)$ axis, indicating optical transitions to states of $B_{2}$ symmetry. If we assume that the geometry during dissociation is similar to that of the ground state, we calculate that complete rotational averaging will yield $\beta<0.19 .{ }^{14}$ From the observed anisotropy of the angular distributions and the large translational energy release, we conclude that dissociation occurs within a rotational period. The $P\left(E_{T}\right)$ distributions are plotted together in Fig. 10. Both distributions appear to have more than one component. The faster component in each distribution dominates, and both have peaks at $E_{\text {int }} \approx 30 \mathrm{kcal} /$ mol. The $P\left(E_{T}\right)$ distribution at $308 \mathrm{~nm}$ has a slow shoulder with a low energy cutoff at $E_{T}=6 \mathrm{kcal} / \mathrm{mol}$, corresponding to $E_{\text {int }}=54 \mathrm{kcal} / \mathrm{mol}$. The faster component of the $248 \mathrm{~nm}$ distribution is similar in shape to the $308 \mathrm{~nm}$ distribution and differs only at low $E_{T}$, where there is a second maximum at $E_{T}=23 \mathrm{kcal} / \mathrm{mol}$ or $E_{\text {int }}=59 \mathrm{kcal} / \mathrm{mol}$. It is likely that the 248 $\mathrm{nm}$ distribution extends to lower translational energies (higher internal energies), where secondary dissociation of $\mathrm{ClO}$ occurs.

In contrast to the longer wavelength distributions, the ClO products from photolysis at $193 \mathrm{~nm}$ are only formed with high internal energies near and above the dissociation limit $\left(E_{\text {int }} \geqslant 33 \mathrm{kcal} / \mathrm{mol}\right)$.

The observation of multiple components in the $P\left(E_{T}\right)$

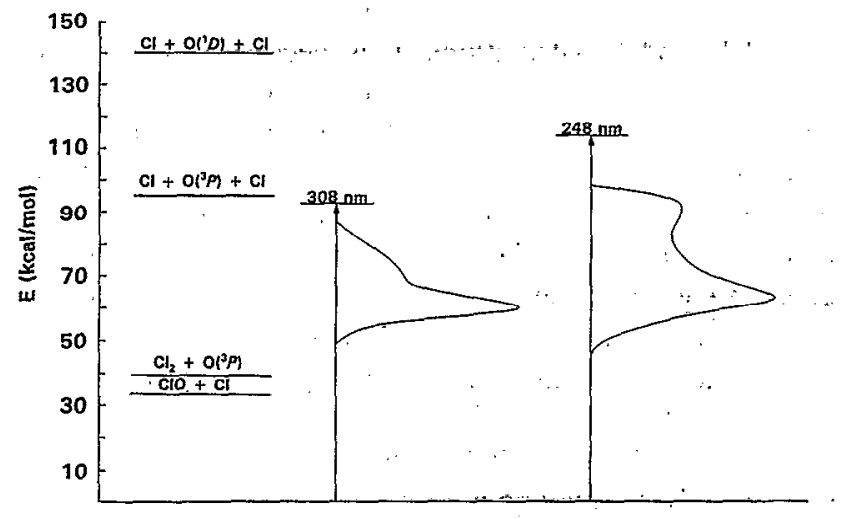

FIG. 10. The encrgy level diagram for the photodissociation of $\mathrm{Cl}_{2} \mathrm{O}$ at 308 and $248 \mathrm{~nm}$. The $P\left(E_{T}\right)$ distributions for $\mathrm{ClO}+\mathrm{Cl}$ are shown to illustrate how the available energy is partitioned at the two wavelengths.

distribution at $248 \mathrm{~nm}$ implies that different dissociation dynamics lead to the same final products $\mathrm{ClO}+\mathrm{Cl}$. The lowenergy shoulder in the $P\left(E_{T}\right)$ distribution at $308 \mathrm{~nm}$ could also be interpreted as a second pathway, but such a conclusion is more tentative. Partially resolved vibrational structure could give the appearance of two components at $308 \mathrm{~nm}$. The fast component in the $248 \mathrm{~nm} P\left(E_{T}\right)$ distribution is similar to the $308 \mathrm{~nm}$ distribution (see Fig. 10) and thus may be attributable to the same dynamical pathway. The second peak at $248 \mathrm{~nm}$ could then be interpreted as products from a new dynamical pathway. On the other hand, the low energy shoulder at $308 \mathrm{~nm}$ could be the onset of a new channel which develops into the second peak at $248 \mathrm{~nm}$ as the photolysis wavelength decreases. These alternatives could be distinguished in a study of the wavelength dependence of the shape of the $P\left(E_{T}\right)$ distribution.

Bimodal distributions can arise if two or more potential energy surfaces are involved in the dissociation. The irregular shape of the absorption spectrum ${ }^{1}$ between 220 and 600 $\mathrm{nm}$ suggests the presence of several electronic states. The strongest bands are at 255 and $\sim 280 \mathrm{~nm}$. It is thus possible to excite two repulsive states of $\mathrm{Cl}_{2} \mathrm{O}$, both of which lead to $\mathrm{ClO}+\mathrm{Cl}$ products. We observe, however, that all components have the same anisotropy, within experimental error. This result is more consistent with excitation to a single electronic state of $\mathrm{Cl}_{2} \mathrm{O}$ followed by a nonadiabatic transition to a second surface. In either case, different excited state surfaces leading to $\mathrm{ClO}+\mathrm{Cl}$ products may correlate to different final spin-orbit states, but our time-of-flight resolution precludes us from distinguishing among the possible spin-orbit channels.

The bimodal distribution could also be explained if $\mathrm{ClO}$ products were formed in an electronically excited state. The report by $\mathrm{Nee}$ and $\mathrm{Hsu}^{20}$ of resolved $\mathrm{ClO}$ fluorescence upon excitation of $\mathrm{Cl}_{2} \mathrm{O}$ in the vacuum ultraviolet indicates that the $\mathrm{ClO}$ photoproduct is formed in several Rydberg states, from the $C$ to the $H$ states. These states are not accessible at the longer wavelengths used in this study. The lowest known excited state of $\mathrm{ClO}$ is the $A^{2} \Pi$ state, but the channel

$$
\mathrm{Cl}_{2} \mathrm{O} \rightarrow \mathrm{ClO}\left(A^{2} \Pi\right)+\mathrm{Cl}\left({ }^{2} P_{3 / 2}\right), \quad \Delta H_{0}^{\circ}=122 \mathrm{kcal} / \mathrm{mol}
$$

is also energetically inaccessible at 248 or $308 \mathrm{~nm}$. 
In order for electronic excitation to account for the observed bimodal distributions, it is necessary to postulate a hitherto unobserved state of $\mathrm{ClO}$ lying below the ground state $\mathrm{ClO}$ dissociation limit. The ground state configuration of $\mathrm{ClO}$ is $(\pi)^{4}\left(\pi^{*}\right)^{3}$, and the $A^{2} \Pi$ state is the only possible molecular state excited by a $\pi^{*} \leftarrow \pi$ transition; however, in halogen compounds, the unoccupied $\sigma^{*}$ orbital is relatively close in energy to the $\pi^{*}$ orbital, and high spin states from a $\sigma^{*} \leftarrow \pi^{*}$ excitation are bound. For example, the lowest excited states of $\mathrm{Cl}_{2}$ are the weakly bound ${ }^{3} \Pi_{J}$ states arising from the $(\pi)^{4}\left(\pi^{*}\right)^{3}\left(\sigma^{*}\right)^{1}$ configuration. These metastable states lie $\sim 7 \mathrm{kcal} / \mathrm{mol}$ below the $\mathrm{Cl}_{2}$ dissociation limit. The existence of an analogous low lying state of $\mathrm{ClO}$ with configuration $(\pi)^{4}\left(\pi^{*}\right)^{2}\left(\sigma^{*}\right)^{1}$ is thus plausible, and would have ${ }^{4} \Sigma$ symmetry. Langhoff has predicted the existence of a weakly bound ${ }^{4} \Sigma^{-}$state in unpublished $a b$ initio calculations performed in the course of an earlier study of $\mathrm{ClO}$ doublet states. ${ }^{21}$ In a recent recalculation, he estimates that this state, the $a^{4} \Sigma^{-}$state, has an energy $T_{0}=51 \mathrm{kcal} / \mathrm{mol}$ above the ground state.

If the theoretical value of $T_{0}$ is correct, formation of $\mathrm{ClO}$ in the $a^{4} \Sigma^{-}$state is energetically allowed in photolysis of $\mathrm{Cl}_{2} \mathrm{O}$ at both 308 and $248 \mathrm{~nm}$. At $308 \mathrm{~nm}$, the energy available for translation upon formation of $\mathrm{ClO}\left(a^{4} \Sigma^{-}\right)$is $E_{\text {avl }}=9$ $\mathrm{kcal} / \mathrm{mol}$, but essentially no products at these low translational energies were observed. At $248 \mathrm{~nm}$, where $E_{\text {avl }}=31$ $\mathrm{kcal} / \mathrm{mol}$, the slower component in the $248 \mathrm{~nm} P\left(E_{T}\right)$ distribution has a maximum at $21 \mathrm{kcal} / \mathrm{mol}$ and thus conceivably could be due to the channel

$$
\left.\mathrm{Cl}_{2} \mathrm{O}+h \nu \rightarrow \mathrm{ClO}\left(a^{4} \Sigma^{-}\right)+\mathrm{Cl}^{2} P\right) \text {. }
$$

These products can only correlate with a triplet state of $\mathrm{Cl}_{2} \mathrm{O}$. Such a state could be formed by a spin - orbit induced Landau-Zener transition occurring at the intersection of an initially prepared singlet surface and a repulsive triplet surface of $\mathrm{Cl}_{2} \mathrm{O}$.

\section{B. The $\mathrm{Cl}_{2}+\mathrm{O}$ channel}

We have presented direct evidence for the concerted dissociation forming $\mathrm{Cl}_{2}+\mathrm{O}\left({ }^{3} \mathrm{P}\right)$ products following excitation at $193 \mathrm{~nm}$. Over $80 \%$ of the $\mathrm{Cl}_{2}$ products undergo spontaneous secondary dissociation in the collisionless conditions of our experiment; the $\mathrm{Cl}_{2}$ products that do reach the detector appear to be highly excited, with $53 \mathrm{kcal} / \mathrm{mol}$ or more of internal energy. The positive anisotropy parameter indicates that the transition moment and recoil vectors are approximately parallel. Given that these vectors are perpendicular to the $a$ axis of this near prolate top, the low value of $\beta$ prevents us from reaching conclusions concerning the time scale of the dissociation. ${ }^{14}$ These observations are consistent with a concerted mechanism occurring on a surface with an early exit barrier, in which the $\mathrm{Cl}-\mathrm{Cl}$ bond would form while the chlorine atoms are still widely separated.

The high internal energy of the $\mathrm{Cl}_{2}$ products could arise if the $\mathrm{Cl}_{2}$ molecules are formed in an electronically excited state. The lowest excited states of $\mathrm{Cl}_{2}$ are the $A, A^{\prime}$, and $B$ states, which are the three $J$ levels of the ${ }^{3} \Pi$ configuration lying $49.1,50.7$, and $50.9 \mathrm{kcal} / \mathrm{mol}$, respectively, above the ground state. Formation of chlorine in any of these states is energetically consistent with the data. Furthermore, the $\mathrm{Cl}_{2}\left({ }^{3} \Pi\right)+\mathrm{O}\left({ }^{3} P\right)$ channel would occur by a spin-allowed process upon initial excitation to a singlet state, whereas the ground state products $\mathrm{Cl}_{2}\left(X^{1} \Sigma\right)+\mathrm{O}\left({ }^{3} P\right)$ would be formed via a spin-forbidden path. Production of triplet chlorine molecules thus provides the simplest explanation for the observed results. If this hypothesis is correct, prompt emission from $\mathrm{Cl}_{2}$ should be observed following $193 \mathrm{~nm}$ photolysis of $\mathrm{Cl}_{2} \mathrm{O}$.

We did not observe the $\mathrm{Cl}_{2}+\mathrm{O}$ channel when photolyzing at 308 or $248 \mathrm{~nm}$, although it is energetically allowed at both wavelengths. A $193 \mathrm{~nm}$ photon excites $\mathrm{Cl}_{2} \mathrm{O}$ in an entirely new band, and it is possible that the barrier for concerted elimination of $\mathrm{Cl}_{2}$ is significantly lower on the new potential energy surface (vide infra).

A concerted dissociation channel has also been observed in the photolysis of OClO in the $300-400 \mathrm{~nm}$ region

$$
\mathrm{OClO}+h \nu \rightarrow \mathrm{Cl}+\mathrm{O}_{2} \text {. }
$$

In contrast to our observations on $\mathrm{Cl}_{2} \mathrm{O}$, Davis and Lee ${ }^{22}$ have found that the $\mathrm{O}_{2}$ product from $\mathrm{OClO}$ appears to be formed with little internal energy, and $\mathrm{O}_{2}$ may in fact be formed in the ${ }^{1} \Delta_{g}$ state. The excited state is predissociative (the absorption spectrum is highly structured), and the angular distribution of photoproducts is isotropic, indicating that the excited molecule lives longer than a rotational period. These conclusions are supported by a recent time-resolved study by Baumert et al. ${ }^{23}$ The dynamics of this concerted dissociation are thus considerably different from those in $\mathrm{Cl}_{2} \mathrm{O}$ dissociation. The mechanism is believed to involve a nonadiabatic transition from the initially prepared state to a highly bent ${ }^{2} B_{2}$ state. ${ }^{24}$ The small bond angle at the minimum energy configuration of this surface favors formation of $\mathrm{O}_{2}$. A similar coupling of electronic states may also be occurring in $\mathrm{Cl}_{2} \mathrm{O}$.

\section{The $2 \mathrm{Cl}+\mathrm{O}$ channel}

We find evidence for complete dissociation of $\mathrm{Cl}_{2} \mathrm{O}$ into three atoms upon excitation at 248 and $193 \mathrm{~nm}$, but not at $308 \mathrm{~nm}$ which lies to the red of the $294 \mathrm{~nm}$ threshold. At 248 $\mathrm{nm}$, this channel occurs by secondary dissociation of the primary $\mathrm{ClO}$ phototragments. Simple bond fission leading to $\mathrm{ClO}+\mathrm{Cl}$ products dominates, and formation of $2 \mathrm{Cl}+\mathrm{O}\left({ }^{3} \mathrm{P}\right)$ products is a minor secondary channel. The $2 \mathrm{Cl}+\mathrm{O}\left({ }^{1} D\right)$ can also occur at high laser fluences by stimulated secondary dissociation of $\mathrm{ClO}$, because $\mathrm{ClO}$ has a large absorption cross section.

In contrast, at $193 \mathrm{~nm}$, almost all of the primary $\mathrm{Cl}_{2}$ photoproducts spontaneously dissociate. ClO that is detected is highly excited and it is probable that most of the primary $\overline{\mathrm{ClO}}$ also undergoes secondary dissociation. Although we could not determine if concerted three body dissociation occurs upon photolysis at $193 \mathrm{~nm}$, we can conclude that photolysis of $\mathrm{Cl}_{2} \mathrm{O}$ at $193 \mathrm{~nm}$ leads predominantly to three atomic fragments in the absence of quenching collisions.

Our results are consistent with early photolysis experiments which found evidence for atomic oxygen photoproducts upon irradiation at wavelengths $\lambda<294 \mathrm{~nm}$. Our findings support Edgecomb et al., ${ }^{7}$ who hypothesized that a 
limited yield of atomic oxygen is formed via the $2 \mathrm{Cl}+\mathrm{O}$ channel in the $235-275 \mathrm{~nm}$ photolysis experiment of Schumacher and Townend. ${ }^{5}$

The quantum yield of $0.25 \pm 0.05$ for atomic oxygen found by Sander and Fried ${ }^{9}$ can also be understood qualitatively. Both channels (2) and (3) contribute to $O$ atom formation because the wavelength range of the xenon flashlamp used to photolyze $\mathrm{Cl}_{2} \mathrm{O}$ extends to $180 \mathrm{~nm}$. At wavelengths just below threshold, but longer than $200 \mathrm{~nm}, 2 \mathrm{Cl}+\mathrm{O}$ products are probably formed by the secondary dissociation of $\mathrm{ClO}$ products. Below $200 \mathrm{~nm}$, additional atomic oxygen is formed by the $\mathrm{Cl}_{2}+\mathrm{O}$ channel (3), but most of the $\mathrm{Cl}_{2}$ also undergoes secondary dissociation. Channel (2) is thus effectively the dominant source of $\mathrm{O}$ atom photoproducts, with dissociation to three atomic fragments probably resulting from secondary dissociation of highly excited diatomic fragments. The relatively low $\mathrm{O}$ atom yield indicates that most of the photolysis occurs at longer wavelengths, a conclusion consistent with the intensity distribution of a xenon flashlamp which decreases rapidly for $\lambda<300 \mathrm{~nm}$. Another possible source of $\mathrm{O}$ atoms, stimulated secondary dissociation of the $\mathrm{ClO}$ products, was not discussed in their paper.

\section{Electronic structure of $\mathrm{Cl}_{2} \mathrm{O}$}

The photoelectron spectrum of $\mathrm{Cl}_{2} \mathrm{O}$ reveals four lowlying molecular orbitals, all within $40 \mathrm{kcal} / \mathrm{mol}(1.7 \mathrm{eV})$ of the highest occupied molecular orbital (HOMO). ${ }^{25}$ The orbitals have been assigned by $a b$ initio calculations, ${ }^{26,27}$. taking into account perturbation corrections to the Koopmans' theorem energies, ${ }^{26}$ and all four contain significant $\mathrm{Cl} p$ character. The highest occupied orbitals in the ground state configuration of $\mathrm{Cl}_{2} \mathrm{O}$ are $\cdots\left(8 a_{2}\right)^{2}\left(9 a_{1}\right)^{2}\left(2 b_{2}\right)^{2}\left(3 b_{1}\right)^{2}$. The lowest unoccupied molecular orbital (LUMO) is the $10 a_{1}$ orbital, which possesses significant $\sigma^{*}(\mathrm{ClO})$ character.

The orbitals are close in energy, and thus assignment of the absorption spectrum is possible only with the aid of calculations that treat electron correlation. Lee has computed energies of the first ten singlet excited states in an $a b$ initio calculation using a coupled-clusters perturbation technique $\operatorname{CCSD}(T){ }^{28} \mathrm{He}$ finds five states below $130 \mathrm{kcal} / \mathrm{mol}$ all with predominantly single excitation character, including one ${ }^{1} B_{2}$ state at $103 \mathrm{kcal} / \mathrm{mol}(276 \mathrm{~nm})$. In a recent multireference configuration interaction calculation, Langhoff also finds a ${ }^{1} B_{2}$ state at $\approx 110 \mathrm{kcal} / \mathrm{mol}(280 \mathrm{~nm})$ with a large transition moment to the ground state, ${ }^{21}$ given the large uncertainties in the calculations, this state is a likely candidate for either the shoulder at $284 \mathrm{~nm}$ or the main band at $255 \mathrm{~nm}$. Langhoff also predicts at least three other dark states, all triplets, below $200 \mathrm{~nm}$. Kuwata et al. identify a high-lying ${ }^{1} A_{1}$ state at $\sim 7$ $\mathrm{eV}$ in a singles-and-doubles configuration interaction (CISD) calculation, and assign it to the absorption band at $171 \mathrm{~nm} .{ }^{29}$

The emerging theoretical picture of the excited states of $\mathrm{ClO}$, while incomplete, qualitatively supports a number of the inferences that we have drawn from the experimental results. If we are exciting to the ${ }^{1} B_{2}$ state at 308 and $248 \mathrm{~nm}$, the transition moment is perpendicular to the $C_{2 v}$ symmetry axis and approximately parallel to the c.m. recoil vector, consistent with the observed values of $\beta$. An electron excited from the $b_{2}$ orbital (weakly antibonding for $\mathrm{ClO}$ ) to the
LUMO [the $\sigma^{*}(\mathrm{ClO}) 10 a_{1}$ orbital] should lead to ClO bond cleavage. The different dynamical pathways leading to the $\mathrm{ClO}+\mathrm{Cl}$ products could be the result of nonadiabatic transitions from an initially prepared state to one of the many predicted dark states. Spin-orbit coupling to one of the triplet states would allow the formation of spin-forbidden products such as quartet CiO.

The transition moment for excitation to the predicted ${ }^{\mathrm{t}} A_{1}$ state at $6.8 \mathrm{eV}$ is parallel to the symmetry axis, consistent with the anisotropy parameter measured for the $\mathrm{Cl}_{2}+\mathrm{O}$ channel at $193 \mathrm{~nm}$. Concerted dissociation leading to $\mathrm{Cl}_{2}$ products is most favored on surfaces with the potential energy minimized at small $\mathrm{ClOCl}$ bond angles. Promotion of an electron from the $b_{2}$ orbital to the $a_{1}$ orbital will decrease this angle bccause the $b_{2}$ orbital is a formally antibonding orbital $\sigma^{*}$ for the $\mathrm{Cl}-\mathrm{Cl}$ bond, while the LUMO $a_{1}$ has $\sigma\left(\mathrm{Cl}_{2}\right)$ bonding character. The doubly excited configuration that involves exciting both $b_{2}$ electrons into the $a_{1}$ orbital will have ${ }^{1} A_{1}$ symmetry. In this configuration, two electrons are promoted from a $\sigma^{*}\left(\mathrm{Cl}_{2}\right)$ orbital into a $\sigma\left(\mathrm{Cl}_{2}\right)$. bonding orbital; therefore, this ${ }^{1} A_{1}$ state is expected to possess an even smaller bond angle than the ${ }^{1} B_{2}$ state. Excitation at 193 $\mathrm{nm}$ to a ${ }^{1} A_{1}$ state could prepare a state with significant admixture of the double $b_{2}$ excitation, or it could be followed by vibronic (Herzberg-Teller) coupling to a $B_{2}$ state; in either case, the potential energy surface would favor small bond angles and a lower barrier for concerted dissociation.

\section{ACKNOWLEDGMENTS}

This work was performed at the Jet Propulsion Laboratory, California Institute of Technology, under contract with the National Aeronautics and Space Administration (NASA), and was supported by the Caltech President's Fund, NASA contract NAS 7-918, National Science Foundation PYI Award CHE-8957243, and a Dreyfus Newly Appointed Faculty Award. C. M. N. acknowledges support of a NASA Graduate Research Fellowship. We thank Timothy Lee and Steven Langhoff for providing unpublished results.

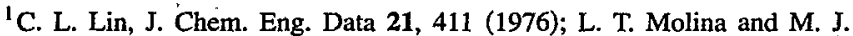
Molina, J. Phys. Chem. 82, 2410 (1978); H. D. Knauth, H. Alberti, and H. Clausen ibid. 83, 1604 (1979).

${ }^{2}$ J. B. Nee; J. Quant. Spectrosc. Radiat. Transfer 46, 55 (1991).

${ }^{3}$ W. Finkelnburg, H. J. Schumacher, and G. Stieger, Z. Phys. Chem. B 15, 127 (1931).

${ }^{4}$ S. Abramowitz and M. W. Chase, Jr., Pure Appl. Chem. 63, 1449 (1991); M. W. Chase, Jr., C. A. Davies, J. R. Downey, Jr., D. J. Frurip, R. A. McDonald, and A. N. Syverud, JANAF Thermochemical Tables, 3rd ed., J. Phys. Chem. Ref. Data 14, Suppl. 1 (1985).

${ }^{5}$ H. J. Schumacher and R. V. Townend, Z. Phys. Chem. B 20, 375 (1933).

${ }^{6}$ F. J. Lipscomb, R. G. W. Norrish, and B. A. Thrush, Proc. R. Soc. London Ser. A 233, 455 (1956); G. G. Freeman and L. F. Phillips, J. Phys. Chem. 72, 3025 (1968).

${ }^{7}$ F. H. C. Edgecomb, R. G. W. Norrish, F. R. S. Thrush, and B. A. Thrush, Proc. R. Soc London Ser. A 243, 24 (1957).

${ }^{8}$ N. Basco and S. K. Dogra, Proc. R. Soc. London Ser. A 323, 401 (1971).

${ }^{9}$ S. P. Sander and R. R. Friedl, J. Phys. Chem. 93, 4764 (1989).

${ }^{10}$ T. K. Minton, C. M. Nelson, T. A. Moore, and M. Okumura, Science 258 , 1342 (1992).

${ }^{11}$ Y. T. Lee, J. D. McDonald, P. R. LeBreton, and D. R. Herschbach, Rev. Sci. Instrum. 40, 1402 (1969); M. J. O'Laughlin, B. P. Reid, and R. K. Sparks, J. Chem. Phys. 83, 5647 (1985).

${ }^{12}$ G. H. Cady, Inorg. Synth. 5, 156 (1957).

${ }^{13}$ R. N. Zare, Mol. Photochem. 4, 1 (1972). 
${ }^{14}$ S.-C. Yang and R. Bersohn, J. Chem. Phys. 61, 4400 (1974).

${ }^{15}$ R. K. Sparks, K. Shobatake, L. R. Carlson, and Y. T. Lee, J. Chem. Phys. 75, 3838 (1981); P. Felder (private communication). The forward convolution program used was FRAGMENT.

${ }^{16}$ R. A. Durie and D. A. Ramsey, Can J. Phys. 36, 35 (1958); H. F. Davis and Y. T. Lee (private communication).

${ }^{17}$ W. B. DeMore, S. P. Sander, D. M. Golden, R. F. Hampson, M. J. Kurylo, C. J. Howard, A. R. Ravishankara, C. E. Kolb, and M. J. Molina, Chemical Kinetics and Photochemical Data for Use in Stratospheric Modeling, Evaluation No. 10, Publication 92-20, Jet Propulsion Laboratory, 1992.

${ }^{18} \mathrm{~K}$. P. Huber and G. Herzberg, Constants of Diatomic Molecules (Van Nostrand-Reinhold, New York, 1977).

${ }^{19}$ G. E. Busch and K. R. Wilson, J. Chem. Phys. 56, 3626 (1972); A. F. Tuck, J. Chem. Soc. Faraday Trans. 2 73, 689 (1977); L. J. Butler, Ph.D thesis, University of California, Berkeley, 1985; C. S. Effenhauser, P. Felder, and J. R. Huber, J. Phys. Chem. 94, 296 (1990).

${ }^{20} \mathrm{~J}$. B. Nee and K. J. Hsu, in Proceedings of the International Conference on
Global and Regional Environmental Atmospheric Chemistry, Beijing, China, May 1989, edited by L. Newman, W. Wang, and C. B. Xiang (Brookhaven National Laboratory, Upton, NY, 1990).

${ }^{21}$ S. R. Langhoff (private communication).

${ }^{22}$ H. F. Davis and Y. T. Lee, J, Phys. Chem. 96, 5681 (1992).

${ }^{23}$ T. Baumert, J. L. Herek, and A. H. Zewail, J. Chem. Phys. 99, 4430 (1993).

${ }^{24}$ K. A. Peterson and H.-J. Werner, J. Chem. Phys. 96, 8948 (1992); J. L. .Gole, J. Phys. Chem. 84, 1333 (1980).

${ }^{25}$ A. B. Cornford, D. C. Frost, F. G. Herring, and C. A. McDawell, J. Chem. Phys. 55, 2820 (1971).

${ }^{26}$ D. P. Chong, F. G. Herring, and Y. Takahata, J. Electron. Spectrosc. Relat. Phenom. 13, 39 (1978).

${ }^{27}$ K. Takano, J. Hosoya, and S. Iwata, J. Am. Chem. Soc. 104, 3998 (1982).

${ }^{28} \mathrm{~T}$. J. Lee (private communication).

${ }^{29} \mathrm{~K}$. Kuwata, W. A. Goddard, and M. Okumura (unpublișhed results). 